\title{
Ssciendo
}

Ethics \& Bioethics (in Central Europe), 2021, 11 (3-4), 231-239

DOI:10.2478/ebce-2021-0020

\section{Healthy people and biochemical enhancement: A new paradigmatic approach to the enhancement of human beings?}

\author{
Zlatica Plašienková1 ${ }^{\text {\& }}$ Martin Farbák $^{2}$
}

\begin{abstract}
The authors analyse a new paradigmatic approach to the enhancement of human beings proposed in transhumanist visions. Transhumanist authors promote the biochemical enhancement of healthy people via the concepts of biohappiness and bio-love (love drugs). The paper is based on an assessment of the value attributed to the lives of disabled people vis-à-vis those of healthy people. The value imbalance in the transhumanist conception is criticized on the grounds that it is an incorrect response to the posthuman urge to redefine human beings. The authors' final standpoint is that the value of human beings should be derived primarily from our naturalness and that artificiality (which is indisputably a part of people) should be subordinate to this.
\end{abstract}

Keywords: transhumanism, biochemical enhancement, disability, value assessment, bio-happiness, bio-love

\section{Introduction}

Enhancement has been part of the history of man from the very beginning. And not just in the history of the human race itself but in the history of life as well. It is a crucial part of evolution. The aim to improve is what Charles Darwin called natural selection, the constant process of ensuring variation between even the most inconsequential things, rejecting the bad and preserving the good, or even perfecting things. He believed that we subconsciously do this whenever and wherever the opportunity presents itself; all organic beings seek to improve themselves concerning the organic and inorganic conditions of life. Unfortunately, we remain unaware of these changes owing to our short life span (Darwin, 1859, p. 84).

Whether we realize it or not, we enhance ourselves, and have always done so as a natural part of our existence. We may not have always used natural tools, but that too can be considered characteristic of our human nature. This is what the German philosopher Helmuth Plessner describes as the law of natural artificiality (Plessner, 1975, pp. 309-321). In short, humans have a constant longing to build their own place in this world and using artificial means to do so is part of our nature.

Besides evolving biologically, we also evolve culturally and that determines how we enhance ourselves. We moved out of huts and into skyscrapers, we swapped our spears for pistols, we replaced horses with cars and shamans with hospitals. The ways in which we enhance ourselves have developed hand in hand with science and technology, as part of our cultural evolution, which is in many ways now overtaking our biological evolution. But the progress in our cultural development is more easily observed than the natural selection described by Darwin. Indeed, we can see that it is accelerating exponentially, which is prompting ethical concerns.

In this paper, we will discuss the new approaches to human enhancement that raise moral questions about the possible adverse consequences. Specifically, we will focus on the visions of biochemical enhancement that have no medical purpose, but are aimed at perfectly healthy people who face some kind of life challenge. This, we believe, is the new paradigm of human enhancement. Never before in human history have there been such realistic visions of how chemicals can be used to change the lives of healthy people in profound biological ways; and yet, there are still many diseases and medical problems that require solutions. Our natural artificiality is advancing very quickly and requires us to engage in some deep philosophical and

\footnotetext{
${ }^{1}$ Comenius University (Slovakia); zlatica.plasienkova@uniba.sk; ORCID: 0000-0003-3201-3722

${ }^{2}$ Comenius University (Slovakia); martin.farbak@uniba.sk; ORCID: 0000-0003-1076-3338
} 
ethical thinking. Historically, there have been numerous paradigmatic turns in the approach towards human enhancement, but the one now standing before us is of a different kind and so should be the subject of philosophical inquiry and investigation in other anthropological disciplines too. Our critical thinking on this topic follows the premise that our biological nature takes priority over our artificiality. We attempt to argue this premise using the example of disabled people.

\section{Biochemical enhancement of human beings - background}

People's lives have changed dramatically in the last few centuries. Science and technological innovations mean that we live longer and are smarter and extremely powerful. Biochemical enhancement is not destined for the cyborgs; most of us are already enhancing our bodies beyond their natural potential. For modern humans, these biochemical advantages are a routine part of our existence; yet our grandparents would have considered them supernatural. The most significant modern innovation insofar as the topic of this paper is concerned is pills. The question is how did herbs end up as pills? American science historian Thomas Hager explains that it all started more than 150 years ago when the first pharmacists and herbalists extracted drugs from barrels of dried plants. The word drug was originally the name of these barrels used for keeping herbs in. The first pharmacists were the first suppliers of effective natural medicines to doctors in the $18^{\text {th }}$ century seeking to help their patients. Today we have more than ten thousand, targeted and increasingly powerful medicines that can "treat and often cure conditions that have confounded healers for thousands of years" (Hager, 2019, p. 7).

When technology became advanced enough for us to put all the effort and hard work originally needed for healing into one small powerful pill, it changed our paradigmatic understanding of the human power to enhance. It was a long journey from having absolutely no understanding of, or power over, disease to decoding human DNA and being able to treat or at least understand almost all diseases. We are now on the verge of the next paradigmatic change - biochemical enhancement has progressed so far that we are considering using it not simply to eliminate diseases but to enhance ordinary life and ease the psychological challenges associated with it.

When fighting illnesses in the past, the options people could choose from were limited. In prehistoric times even resting could be considered enhancement since it was the first (and very often the only) means of fighting the disease. Those who did have the luxury of long-term convalescence without starving to death could enhance their life conditions to above average. We may not realize it in the current era of paid sick leave but our ancestors did not have the opportunity to get time off work and rest while being supplied with all the necessities of life. The urge to hunt for food to feed the individual as well as the family was much stronger then than it is today. The first global pandemic in the modern era - Covid-19 - is illustrative of the social change that has occurred over time. While most people living in previous centuries had to grow their own food, nowadays, thanks to innovations in food production and distribution, most people are unaware of the time and seasonal pressures connected with agricultural production. ${ }^{3}$ Obviously, there are other types of pressures that force us to work despite being ill, but the research shows we often tackle these by taking over-the-counter painkillers such as paracetamol or ibuprofen (Simundic et al., 2020). This is another example of the paradigmatic shift. Whereas rest was previously considered a costly way of healing and the enhancement was simply resting without the negative consequences, nowadays the answer lies in pills bought in a store that are capable of suppressing the symptoms of sickness and fatigue.

\footnotetext{
${ }^{3}$ Far fewer farmers are needed to feed many more people thanks to food production innovations. According to the United Nation's Food \& Agriculture Organization the world's farmers can now produce enough food to provide every person with more than 2,700 calories per day. That means we could even feed an additional billion people (United Nations Food \& Agriculture Organization, 2010).
} 
The distinction between over-the-counter (OTC) medications and prescription medications represents an important step towards the current transhumanist visions of biochemical enhancement, which are the outcome of these paradigmatic shifts. Initially, most drugs were available without a prescription because there were only a few of them and they were quite simple, although little was known about them. With further advances in medicine and the expansion of drug use for medical purposes, clear guidelines were issued as to which drugs could be sold by prescription only and which could be sold over the counter. Prescription drugs were defined as compounds that could be unsafe, except when used under a doctor's supervision. Anything else could be sold over the counter. But questions remain as to whether some OTC drugs should be accessible without regulation. This applies especially to paracetamol or ibuprofen and the potential for misuse (Frei et al., 2010). A less discussed issue concerning OTC drugs is that their overuse and misuse has become socially acceptable and normalized. The risks of the potential side effects are underestimated, which is connected to the weak vigilance towards this kind of biochemical enhancement. The above-mentioned historian Thomas Hager suggested that we should perhaps rename our species Homo pharmacum, the species that makes and takes drugs. He said, "we are the People of the Pill" (Hager, 2019, p. 6).

This brief explanation of the background to the current paradigmatic turn in what we understand by human biochemical enhancement began at a time when there was no biochemical enhancement at all, proceeded through the period when herbs were used to treat common diseases and ended with the present era of biochemical treatments for lifestyle diseases. What is the next step? Medications are regularly misused and overused as we strive to keep up with our hectic lifestyles, and chemical substances have become a permanent part of our social habits. It is not surprising therefore to find that there are transhumanist visions of the human future in which chemicals are not used simply to fight disease or treat other medical problems but to artificially enhance healthy people.

\section{Transhumanist visions of the biochemical enhancement of human beings}

Transhumanism is a relatively new philosophical, cultural and scientific movement that arose in the late 1980s and early 1990s. Francesca Ferrando from New York University explains that the transhumanism movement:

...problematizes the current understanding of the human not necessarily through its past and present legacies, but through the possibilities inscribed within its possible biological and technological evolutions (Ferrando, 2013, p. 27).

Ferrando points out that transhumanism ${ }^{4}$ is a response to the urgent need for an integral redefinition of the notion of the human being in the evolving environment of interconnected existence that is related to the onto-epistemological developments of the twentieth and twentyfirst centuries (Ferrando, 2013, p. 32). It is what we call an onto-epistemological crisis and presents a challenge to us all. The interconnected existence is linked to the current info-era that began in tandem with the advances in information technologies. Unfortunately, this interconnected existence comes at the expense of the personal existence of human beings. The epistemological ability to understand the world in which we humans live is hampered by the enormous increase in the availability and quantity of information from countless resources. ${ }^{5}$

\footnotetext{
${ }^{4}$ Ferrando used the notion of transhumanism that comes under the term of posthumanism. The distinction between transhumanism and posthumanism lies in the difference in emphasis on science and technology. In posthumanism technology is not the main focus, whereas in transhumanism science and technology are the main subjects of interest insofar as the redefinition and enhancement of human beings is concerned.

${ }^{5}$ More about the epistemological issues discussed here can be found in a special issue of the Journal of Futures Studies, "The internet, epistemological crisis and the realities of the future: An introduction to this special" (Ramos \& Nycyk, 2020).
} 
Since most crucial pieces of information are globally interconnected and the certainty of any of them is regularly questioned, it is very difficult for individuals to create their own worldview and to anchor their comprehension of the ontological aspects of their existence. The epistemological and ontological questions in human life are moving apart and it is increasingly harder to find the harmony between them in seizing one's existence. Transhumanism is a response to this onto-epistemological crisis, but it puts the emphasis entirely on science and technology. Within that we can identify two main fields: bio-engineering and techno-cybernetic enhancement. Biochemical enhancement comes under bio-engineering.

These are the transhumanist visions of biochemical enhancement that represent the current paradigmatic change in our understanding of humans. They are closely related to two of the most important components of existence: happiness and love. ${ }^{6}$

The vision of enhanced happiness is a complex socio-political and philosophical theory. It consists of the idea that everybody living in a democratic state should have free access to happiness pills. These pills would contain two main active substances - serotonin and dopamine. It is believed, and the scientific research shows, that these two hormones are responsible for the feelings of happiness induced in our brain. The main advocate of this vision is Mark Walker, who bases it on studies that show a correlation between the level of happiness and the level of pro-social behaviour (Walker, 2007, pp. 201-203). The idea is that taking these happiness pills would both benefit those who take them and they in turn would then promote positive values in society. Happy-people-pills are supposed to address the root problem of humanity - the lack of goodwill - and, in theory, enhancing our biologically determined happiness should boost the fight for greater social justice. ${ }^{7}$

Consuming different kinds of food, drink, herbs or chemicals to generate good feelings is not a new concept, but doing it so we act better is. People have always tried to make life easier by consuming different things. Coffee is a good example. It does us no harm and, moreover, it has positive effects on our health and we drink it to get a daily energy boost. The proponents of bio-happiness (biochemically induced happiness) believe that the happy-people-pills would pose no higher risk than drinking a cup of coffee, but would have more significant and useful effects at the same time.

A similar example is the use of cannabidiol (CBD), which has already become reality with the granting of legal approval in many countries. It is similar to the transhumanist vision of biohappiness. The long discussions about the legal use of the cannabis plant (marijuana) have ended in consensual agreement. CBD or cannabidiol is the second most active ingredient in cannabis, but most importantly it is not psychedelic nor psychotropic. The World Health Organization confirmed that CBD has "no effects indicative of any abuse or dependence potential" (World Health Organization, 2017, p. 5). Many studies have confirmed that it has a positive impact on physical and mental health (for example Maroon \& Bost, 2018 or Morales \& Reggio, 2019) and it is now legal in many countries for clinical use at least, with free use being regulated to varying degrees. It has become a new hit among managers with high-stress jobs. Eos Scientific conducted national representative research across a sample of more than 2,000 British adults to examine how job-related stress levels affect our health. One finding was that $38 \%$ of workers in high-stress careers would consider using CBD to treat their mental

\footnotetext{
${ }^{6}$ Our deeper research into the biochemical enhancement of love and happiness can be found in our previous works (Plašienková \& Farbák, 2020; Plašienková \& Farbák, 2021) in which we (among other things) critically consider the transhumanist vision of the chemical future of relationships induced by Love drugs as proposed by Brian D. Earp and Julian Savulescu (Earp \& Savulescu, 2020) and the vision of Happy-People-Pills for All, the term created by Mark Walker in his manifesto of the biochemical enhancement of happiness (Walker, 2013).

${ }^{7}$ It would be interesting to analyse Walker's conception in relation to the ethics of social consequences that was developed by Vasil Gluchman. In this context, his paper about Moore's contributions to the development of the theory of moral/right action may prove inspirational in the analysis of ethical problems (Gluchman, 2017, p. 62).
} 
health and many of them already do. ${ }^{8}$ Are we just a few steps away from governments distributing happy-people-pills to citizens to induce pro-social behaviour, as Mark Walker envisioned (Walker, 2007)?

Another transhumanist vision of how humans can be biochemically enhanced is to be found in Love drugs. Brian D. Earp and Julian Savulescu, the authors of the book Love drugs - the chemical future of relationships (Earp \& Savulescu, 2020), suggest that chemical substances should be used in psychological therapy for couples dealing with a relationship crisis. They specifically mention the chemical compound $\mathrm{MDMA}^{9}$ and the hormone Oxytocin. Earp and Savulescu propose a vision in which couples faced with the loss of mutual love emotions and passion, so-called "grey relationships", could undergo specialist-directed pair therapy and take low doses of these drugs. When properly directed the effects of such drugs could help couples rediscover the initial spark between them (Earp \& Savulescu, 2020, p. 81).

Both of these visions are based on a similar understanding of ontological and existential phenomena such as happiness and love - that they are genetically and biologically determined (Hughes, 2004, p. 48) and so can be enhanced or induced through various external interventions. We believe that if we are to understand the role of happiness and love in human life we cannot ignore their ontological essence and importance in answering existential questions. The experience of having a loving and intimate relationship or being happy is integral to people as relationship-based beings within the complexity of their biological, psychological, sociocultural and spiritual structure. We have a natural ability to relate to ourselves, to others and to the whole world in which we realise our existence. This ability allows us to keep our distance and to unlock our potential to understand ourselves, others and the world. In this process, we maintain our sense of the continuity of life and integrity. Hand in hand with authenticity we continuously form our personal integrity by gradual overcoming life's challenges. This personal integrity is also constituted (sometimes exclusively) in situations that cause us pain and suffering (Plašienková, 2015, p. 37). But these issues are not addressed in the works of transhumanist visionaries.

Science has already changed our perception of the use of chemicals to enhance our lives. We automatically seek help in a pill when we have a headache, when we cannot sleep or when we want to prevent car sickness. We have extensively pushed the boundaries between naturalness and artificiality in the last decades, and although this is done under strict medical research into the possible biological impacts on our bodies and brains, we lack answers to our ontological questions. As we said at the beginning, we believe that enhancement is an indelible part of human life, but that there is a need for deeper philosophical-ethical and critical reflection so we can find the right balance of naturalness and artificiality.

\section{Enhancing healthy people: Why not?}

We have been examining the biochemical enhancement of healthy people and the correct balance between naturalness and artificiality. But to explain why it can be considered a new paradigmatic approach in human enhancement we will compare the transhumanist assessments of disabled and healthy people.

In the transhumanist vision of the ideal future world, there will be no disease or disabilities (but at what price?). Anything connected to suffering is to be eradicated with the help of science and technology (not just through biochemical enhancement) and transhumanists believe this

\footnotetext{
${ }^{8}$ The full title of the research is Brits in high-stress careers would consider CBD oil for mental health (Open Access Government, 2020).

${ }_{9}^{9}$ 3,4-methylenedioxymethamphetamine (commonly known as ecstasy, E, X, or Molly). MDMA was synthesized by a German pharmaceutical company in 1912 during research into new haemostatic (blood-clotting) agents. Chemists later investigated the compound's pharmacological potential. Since this research did not reveal anything of particular interest, MDMA was not developed for clinical use, but was later discovered as a party drug (Meyer, 2013, pp. 83-84).
} 
will become possible at some point if we allow the artificial evolution of humans. According to this value assessment of suffering, the lives of disabled people are less valuable because of the inconveniences associated with being disabled and so it is better to either prevent the birth of such people or not prolong their life. To demonstrate our case, we can refer to the academic polemic between Peter Singer and Harriet McBryde Johnson. Their discussion started after Singer gave a lecture on Rethinking Life and Death at the College of Charleston in 2001. Singer defended a position that was met with vehement opposition. He defended the position of physicians who routinely withdraw life support from severely disabled newborns. ${ }^{10} \mathrm{He}$ argued that:

This is not very different from allowing parents to decide, in consultation with their doctors, to end the life of a baby when the child has disabilities so serious that the family believes this will be best for the child or for the family as a whole (Singer, 2016, p. 205).

He was opposed by Johnson, a supporter of Not dead yet, a disability rights organization, who had neuromuscular disease and was severely disabled herself. She argued that if her parents had been permitted to end her life support after she was born, she would not have become an attorney and, more importantly, a person who enjoyed life. She claimed that it would be a mistake to believe that having a disability makes life less worth living and she developed this idea in her personal memoir Too late to die young (Johnson, 2005). The reasoning behind the value assessment informing Singer's opinion may seem correct, but Johnson opposed it on the grounds that it was controversial decision-making about human value.

Our concern is that transhumanism does not attach a fixed moral value to a human person. ${ }^{11}$ The value is assigned to the person's life conditions rather than their existence, and that is problematic because it could lead to extreme outcomes in a politically unstable world. The comparison in this paper between the transhumanist approaches to disability and the biochemical enhancement of healthy people is illustrative of the paradigmatic turn we mentioned. The role science and technology can play to the benefit of disabled newborns is underestimated; some would rather end such lives without giving them a chance. Yet they would use scientific and technological achievements to help perfectly healthy people overcome common difficulties that people have been dealing with for centuries. This discrepancy originates in the new paradigmatic understanding of human value and it may be very wrong.

John Harris from the University of Manchester defends the same standpoint as Peter Singer on withdrawing life support from severely disabled newborns (Harris, 2001, p. 383). His critics, led by Tom Koch from the University of British Columbia, have argued strongly against such a standpoint. Koch's arguments can be summarized in the statements below, and we consider them to be correct:

1) The elimination of persons with disabilities - especially those with genetic distinctions (Motor Neuron disease, Huntington's, etc.) - would deprive society of important members (for example Stephen Hawking).

2) Physically distinguishable conditions of disabled people may provide the impetus for a rich life. The "harm" of life under the burden of disability is balanced, and in some cases outweighed, by the resulting "benefit".

3) Disability can act as a catalyst for positive social change, which can have a great impact on society (Koch, 2002, p. 203).

\footnotetext{
${ }^{10}$ Singer's approach to death in cases involving brain death differs in that he follows the evidence that clearly shows that brain death is not equivalent to the death of the human organism but equivalent to a human irreversibly losing consciousness (Singer, 2018, p. 163).

${ }^{11}$ Another good example in support of this statement is the concept of procreative beneficence defended by Julian Savulescu (Savulescu, 2007), which was heavily criticized by Rebecca Bennett (Bennett, 2009).
} 
Harris' view was also criticized by professor of bioethics Rebecca Bennett, who said:

If we have a moral obligation to choose against individuals with disability, not because of concern for their own welfare but because a world without disability is a morally preferable place, then this inevitably places a lower value on those living with disabilities (Bennett, 2014, p. 30).

Harris responded to his critics by formulating one principle and three fallacies, of which he was then accused of making. The principle concerns the equality of all people and Harris agreed with it. All persons are equal and no one is less equal than others. No disability - slight or severe - implies a lesser ethical status, worth or value.

The three fallacies Harris was accused of (Harris, 2001, p. 383) can be reformulated like this:

1) Choosing not to repair damage or dysfunction or not to enhance the functioning of a disabled person implies either that their state is incompatible with life or that the person in that state is of lesser value, or it indicates that the individual has a life that is not worth living.

2) The aim to artificially produce children who will be either less damaged or diseased, or more healthy, or who will have enhanced capacities, violates the principle of equality.

3) Disability or impairment should not be defined relative to normal species functioning or species-typical functioning.

Even though Harris disagreed with the accusation, we believe (together with his critics) that these fallacies appear in his conception as well as in transhumanist visions of human enhancement.

\section{Conclusions}

In this paper, we have discussed what we call a new paradigmatic approach to the enhancement of humans. It is embodied in the attempts of transhumanist authors to enhance healthy people via the visions of bio-happiness and bio-love (love drugs), even though it is not necessary for their survival and may even have adverse consequences for their existence. The example given here of people with disabilities who are able to embrace their lives with love and happiness, and fill them with meaning (for instance Harriet McBryde Johnson or Stephen Hawking) gives us a clearer sense of why the paradigmatic approach of transhumanist visions that seek to biochemically enhance healthy people is unacceptable. In such a paradigm, the hierarchy of life values changes completely. The value of life's conditions, such as suffering, is not understood properly and this means that the transhumanist vision has unrealistic outcomes. It proposes that scientific and technological achievements should serve not severely disabled humans but rather perfectly healthy people. Our final standpoint is that the value of human beings should be derived primarily from our naturalness and that artificiality (which is indisputably a part of us) should be subordinate to that. Our critical assessment is that the value imbalance in the transhumanist conception provides the wrong answer to the current onto-epistemological crisis and redefines the notion of humans and their place in the future world. It misunderstands the scientific and bio-technological developments of the twentieth and twenty-first centuries.

\section{Acknowledgment}

This paper was supported by the Slovak research and development agency under contract no. APVV-18-0103: Paradigmatic changes in the understanding of universe and man from philosophical, theological, and physical perspectives. 


\section{References}

BENNETT, R. (2009): The fallacy of the principle of procreative beneficence. In: Bioethics, 23(5), pp. 265-723.

BENNETT, R. (2014): There can be no moral obligation to eradicate all disability. In: Cambridge Quarterly of Healthcare Ethics, 23(1), pp. 30-40.

BRITS IN HIGH-STRESS CAREERS WOULD CONSIDER CBD OIL FOR MENTAL HEALTH. Open Access Government [online]. Adjacent Digital Politics Ltd, C2020 [Retrieved October 2, 2020]. Available at: https://www.openaccessgovernment.org/high-stress-careerscbd-oil/62714/

DARWIN, CH. (1859): On the origin of species. London: John Murray.

EARP, D. B. \& SAVULESCU, J. (2020): Love drugs: The chemical future of relationships. Stanford: Redwood Press.

FERRANDO, F. (2013): Posthumanism, transhumanism, antihumanism, metahumanism, and new materialisms differences and relations. In: Existenz, 8(2), pp. 26-32.

FREI, Y. M. (2010): Serious morbidity associated with misuse of over-the-counter codeineibuprofen analgesics: a series of 27 cases. In: Medicine and the Community, 193(5), pp. 294-296.

GLUCHMAN, V. (2017): G. E. Moore and theory of moral/right action in ethics of social consequences. In: Ethics \& Bioethics (in Central Europe), 7(1-2), pp. 57-65.

HAGER, T. (2019): Ten drugs: How plants, powders, and pills have shaped the history of medicine. New York: Abrams Press.

HARRIS, J. (2001): One principle and three fallacies of disability studies. In: Journal of Medical Ethics, 27(6), pp. 383-387. [online] [Retrieved October 2, 2020] Available at: https://jme.bmj.com/content/medethics/27/6/383.full.pdf

HUGHES, J. (2004): Citizen cyborg, why democratic societies must respond to the redesigned human of the future. Cambridge: Westview Press.

JOHNSON, M. H. (2005): Too late to die young: nearly true tales from a life. New York: Henry Holt and Co.

KOCH, T. (2002): Debate. One principle and three fallacies of disability studies. In: Journal of Medical Ethics, 28(3), p. 203. [online] [Retrieved October 2, 2020] Available at: https://europepmc.org/backend/ptpmcrender.fcgi?accid=PMC1733588\&blobtype=pdf

MAROON, J. \& BOST, J. (2018): Review of the neurological benefits of phytocannabinoids. In: Surgical neurology international, 9(1), p. 91. [online] [Retrieved October 2, 2020] Available at: http://surgicalneurologyint.com/wp-content/uploads/2018/05/8851/SNI-9-91.pdf

MEYER, S. J. (2013): 3,4-methylenedioxymethamphetamine (MDMA): current perspectives. In: Substance Abuse and Rehabilitation, 4, pp. 83-99. [online] [Retrieved October 2, 2020] Available at: https://www.ncbi.nlm.nih.gov/pmc/articles/PMC3931692/pdf/sar-4-083.pdf

MORALES, P. \& REGGIO, H. P. (2019): CBD: A new hope? In: ACS Medicinal Chemistry Letters, 10(5), pp. 694-695. [online] [Retrieved October 10, 2020] Available at: https://pubs.acs.org/doi/pdf/10.1021/acsmedchemlett.9b00127

PLAŠIENKOVÁ, Z. (2015): Zmysel života a jeho problematizácia v horizonte transcendencie a imanencie [The meaning of life and its problematization in the horizon of transcendence and immanence]. In: J. Šlosiar, M. Palenčár \& M. Duško (eds.): Osamelost’v kontexte zmyslu života [Loneliness in the context of the life]. Banská Bystrica: Belianum, pp. 35-50.

PLAS̆IENKOVÁ, Z. \& FARBÁK, M. (2020): Chemical dehumanisation of love vs authentic evolution of love. In: Philosophy and Public Issues, 10(3), pp. 227-252.

PLAŠIENKOVÁ, Z. \& FARBÁK, M. (2021): Happiness issue - moral aspects of its biochemical enhancement. In: Studia Ecologiae et Bioethicae, 19(3), pp. 17-24. 
PLESSNER, H. (1975): Die Stufen des Organischen und der Mensch. Einleitung in die Philosophische Anthropologie [The levels of organic life and the human: Introduction to philosophical anthropology]. Berlin: Walter de Gruyter.

RAMOS, J. \& NYCYK, M. (2020): The internet, epistemological crisis and the realities of the future: An introduction to this special issue. In: Journal of Futures Studies, 24(4), pp. 1-4.

SAVULESCU, J. (2007): In defence of procreative beneficence. In: Journal of Medical Ethics, 33(5), pp. 284-288.

SIMUNDIC, M. A. et al. (2020): Patient's knowledge and awareness about the effect of the over-the-counter (OTC) drugs and dietary supplements on laboratory test results: A survey in 18 European countries. In: Laboratornaya sluzhba, 9(1), pp. 96-107.

SINGER, P. (2016): Ethics in the real world. Princeton: Princeton University Press.

SINGER, P. (2018): The challenge of brain death for the sanctity of life ethic. In: Ethics \& Bioethics (in Central Europe), 8(3-4), pp. 153-165.

UNITED NATIONS FOOD \& Agriculture Organization (2010). Agriculture and food security. Rome: Faostat. [online] [Retrieved October 1, 2020] Available at: https://www.fao.org/3/x0262e/x0262e05.htm

WALKER, M. (2007): Happy-people-pills and prosocial behaviour. In: Philosophica, 79(1), pp. 93-111. [online] [Retrieved October 12, 2020]. Available at: $<$ http://www.philosophica. ugent.be/fulltexts/79-7.pdf.>.

WALKER, M. (2013): Happy-People-Pills for All. New York: John Wiley \& Sons Inc.

WORLD HEALTH ORGANIZATION (2017): Cannabidiol (CBD). Pre-review report. Geneve: Expert Committee on Drug Dependence. [online] [Retrieved October 2, 2020] Available at: https://www.who.int/medicines/access/controlled-substances/5.2_CBD.pdf 